\title{
Corrigendum: The intersection of disability and food security: Perspectives of health and humanitarian aid workers
}

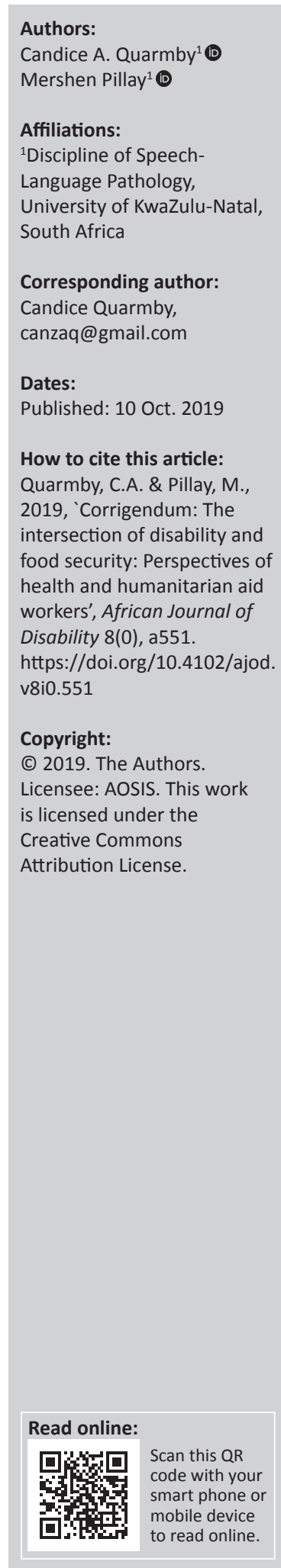

\section{Authors:}

Affiliations:

${ }^{1}$ Discipline of Speech-

Language Pathology,

, Katul,

Candice Quarmby,

Dates:

Quarmby, C.A. \& Pillay, M.,

food security: Perspectives of

health and humanitarian aid

https://doi.org/10.4102/ajod.
In the version of this article initially published, Candice A. Quarmby's affiliation was incorrectly mentioned as Disciplines of Audiology \& Speech-Language Therapy, University of KwaZuluNatal, South Africa. Her correct affiliation is Discipline of Speech-Language Pathology, University of KwaZulu-Natal, South Africa. The error has been corrected in the PDF version of the article. The author apologises for any inconvenience that this omission may have caused. 